\title{
Timeliness of care received by children with speech and language disorders attending a speech therapy clinic at a tertiary care hospital
}

\author{
W D Y N Walpita ${ }^{1}$, Samitha Ginige ${ }^{2}$ \\ Sri Lanka Journal of Child Health, 2014; 43(3): 147-153
}

\begin{abstract}
Introduction: Speech and language therapy is an evolving field in the Sri Lankan health setting which enhances the quality of life of speech disabled children. However, timely identification and intervention is a key determinant in the success of speech therapy.
\end{abstract}

Objective: To assess the timeliness of care received by children with speech and language disorders attending the Speech and Language Therapy Clinic at the Lady Ridgeway Hospital for Children, Colombo.

Methods: A cross-sectional study design was used to collect data on timeliness of disease identification, care seeking and referral as well as the sources of identification, care seeking and referral. The time gaps between identification, care seeking and referral were calculated. Factors associated with timeliness of identification and the differences of time gap between various sub groups were analyzed.

Results: Mean ages of identification, care seeking and referral of speech/language disorder were 15.3, 18.3 and 24.3 months respectively. Female sex, higher maternal education, being an extended family, positive family history and having an associated condition were significantly associated with earlier age of identification. The Medical Officer of Health team was involved in identification of only 11 (4.3\%) children, despite the frequent encounters.

The time gap between identification and care seeking was more than 3 months in $102(40 \%)$ subjects. Multilingual family and having an employed mother were significantly associated with lesser time gap. The time gap between seeking of care and referral for speech therapy was more than 3 months in 96 (41.6\%). Most (57.1\%) parents had sought care from

${ }^{1}$ Registrar in Community Medicine, Postgraduate Institute of Medicine, University of Colombo, ${ }^{2}$ Consultant Epidemiologist, Epidemiology Unit, Colombo

(Received on 5 September 2013: Accepted after revision on 25 October 2013)

a doctor or other health worker in the primary health care setting. However, 236 (92.5\%) of referrals were by a child specialist within or outside Lady Ridgeway Hospital. Altogether $79.6 \%$ of the study sample was referred for speech therapy before the age of 3 years.

Conclusions: Current timeliness of disease identification and age of intervention is satisfactory but there is room for improvement with regard to the valuable time lost between identification to care seeking and referral.

(Key words: Speech and language therapy; children; timeliness)

\section{Introduction}

To communicate effectively, children must master language, i.e. the conventional code used to convey thoughts and ideas, and speech, the complex and rapid motor movements that translate such ideas into spoken words ${ }^{1}$. Globally, approximately $6 \%$ of children have speech and language difficulties ${ }^{2}$. Local studies have reported a $3-8 \%$ burden of communication problems in children ${ }^{3,4}$.

Speech/language disorder is one of the disabilities where effective interventions are available, if diagnosed and intervened timely, especially in children $^{5,6}$. Early intervention for communication delays is defined as "Intervention in the form of assessment and/or treatment provided to families and their children below the age of three years, who demonstrate, or are at-risk for demonstrating, either a disability or delay involving communication" $" 7,8$. Early identification and intervention have been shown to be associated with better long-term outcomes and to assist in educational planning ${ }^{5,6,9}$.

Age at care seeking, as well as age of referral could be markedly different from age at identification ${ }^{10,11}$. However, many children with clinically identifiable developmental problems present late for medical help due to low rate of early recognition ${ }^{12}$. Further, there is no proper pathway of referral identified. Consequently, there is an identification and communication gap which leads to late diagnosis and referral ${ }^{13}$. 
In 1998, a 2 year diploma course was started in Sri Lanka to produce university educated speech and language therapists (SLTs) through collaboration between Sri Lankan and British academics and the Sri Lankan Ministry of Health ${ }^{14}$. The first set of graduates were absorbed into the government health care system in 2000 after which speech and language therapy clinics were started in major hospitals. In 2008, the diploma course was upgraded to a 4-year degree programme. Currently, there are about 65 SLTs working in Sri Lanka in various medical and non medical settings. However, more than two thirds of SLTs from all sectors are either working in Colombo or the suburbs ${ }^{15,16}$.

Currently there is no proper community screening programme for detection of speech disordered children. The Speech and Language Therapy Clinic at the Lady Ridgeway Hospital for Children (LRH), Colombo, is a national referral centre catering exclusively for children with speech disorders coming from all over Sri Lanka.

\section{Objective}

To assess the timeliness of care received by children with speech and language disorders attending the Speech and Language Therapy Clinic at LRH.

\section{Method}

A descriptive cross-sectional study design was used. All child-caretaker pairs attending the speech therapy clinic at LRH from $16^{\text {th }}$ August 2010 to $15^{\text {th }}$ of September 2010 on all days that the clinic was conducted were included in the study. They were identified by using the clinic attendance register. Two study instruments were used for data collection. One was an interviewer administered questionnaire which was administered to the child-caretaker pairs and the other was a data extraction form which was filled by the data collectors using the clinic records of the same patient. Questionnaire was prepared after reviewing the literature, and with the support of local experts on the subject including speech therapists, senior lecturer in speech therapy, ENT surgeon and a child psychiatrist. The content was planned according to the objectives and pre testing was done.

Prior to analysis appropriate frequency distributions and cross tabulates were made to match the objectives. Data were processed and analyzed using SPSS software $\left(17^{\text {th }}\right.$ version). The percentages were calculated for the descriptive elements and the means and the difference between the means with confidence intervals and $\mathrm{p}$ values were assessed for the analytic components. The level of significance was taken as $p<0.05$. Ethical approval was obtained from the Ethics Review Committee of LRH.

\section{Results}

Questionnaires were administered to 265 subjects and the response rate was $96.2 \%$. Out of the 255 respondents, $197(77.3 \%)$ were mothers and the rest were fathers as it was compulsory for a parent to be present at the therapy session. Of all study subjects, $157(61.6 \%)$ were boys and $98(38.4 \%)$ were girls. The ages at initial identification of speech/language disorders is shown in table 1.

Table 1

Ages at initial identification of speech /language disorders

\begin{tabular}{|c|c|}
\hline $\begin{array}{c}\text { Age at initial identification } \\
\text { (months) }\end{array}$ & Frequency (\%) \\
\hline$<12$ & $109(42.7)$ \\
\hline $13-24$ & $79(31.0)$ \\
\hline $25-36$ & $44(17.3)$ \\
\hline $37-48$ & $17(06.7)$ \\
\hline $49-60$ & $04(01.6)$ \\
\hline $61-72$ & $0(0)$ \\
\hline $73-84$ & $0(0)$ \\
\hline $85-96$ & $0(0)$ \\
\hline $97-108$ & $02(0.8)$ \\
\hline Total & $\mathbf{2 5 5}$ \\
\hline
\end{tabular}

The mean age at identification was 15.3 (SD13.3) months. In $43 \%$ the speech/ language disorder was identified in infancy and by 3 years $91 \%$ were identified to have some sort of a speech disability (table 1).

The differences between mean ages of initial identification in selected groups are shown in table 2 
Table 2

Differences between mean ages of initial identification in selected groups

\begin{tabular}{|l|c|c|c|}
\hline \multicolumn{1}{|c|}{ Compared groups } & $\begin{array}{c}\text { Difference of mean } \\
\text { ages (months) }\end{array}$ & $\begin{array}{c}\text { CI for the } \\
\text { difference }\end{array}$ & Significance \\
\hline Male / Female & 5.03 & $2.01-8.06$ & $\boldsymbol{P}=\mathbf{0 . 0 0 1}$ \\
\hline Birth order=1 / Birth order $>1$ & -2.72 & $(-5.98)-0.55$ & $\mathrm{P}=0.100$ \\
\hline Unilingual Families / Bi/trilingual families & -2.41 & $(-7.04)-2.21$ & $\mathrm{P}=0.306$ \\
\hline Social class 1\&11 / Social class 111,1V,V & 0.09 & $(-3.2)-3.4$ & $\mathrm{P}=0.955$ \\
\hline Father's educational level $<\mathrm{O} / \mathrm{L} /$ Passed O/L or above & 2.21 & $1.14-9.71$ & $\boldsymbol{P}=\mathbf{0 . 0 1 3}$ \\
\hline Mother's educational level<O/L / Passed O/L or above & 5.43 & $1.16-13.04$ & $\boldsymbol{P}=\mathbf{0 . 0 2 0}$ \\
\hline Family history negative / Family history positive & 7.10 & $5.64-11.83$ & $\boldsymbol{P}=\mathbf{0 . 0 0 0}$ \\
\hline Nuclear family / Extended family & 8.74 & $-8.09-(-17.29)$ & $\boldsymbol{P}=\mathbf{0 . 0 0 0}$ \\
\hline Associated condition + / Associated condition - & -12.69 & $(-3.5)-2.8$ & $\mathrm{P}=0.824$ \\
\hline Milestones marked in CHDR / Never marked & -0.36 & $\mathrm{P}=0.295$ \\
\hline
\end{tabular}

The distribution of the sources of initial identification is shown in table 3 .

Table 3

Sources of initial identification

\begin{tabular}{|l|c|}
\hline \multicolumn{1}{|c|}{ Source } & Frequency (\%) \\
\hline Father & $25(09.8)$ \\
\hline Mother & $09(03.5)$ \\
\hline Relative/friend & $06(02.4)$ \\
\hline Teacher & $04(01.6)$ \\
\hline General Practitioner & $04(01.6)$ \\
\hline Medical Officer of Health & $07(02.7)$ \\
\hline $\begin{array}{l}\text { Public Health Midwife /Public } \\
\text { Health Nurse }\end{array}$ & $119(46.7)$ \\
\hline $\begin{array}{l}\text { Doctor / Hospital Staff while on } \\
\text { treatment for something else }\end{array}$ & $\mathbf{2 5 5 ( \mathbf { 1 0 0 } )}$ \\
\hline \multicolumn{2}{|c|}{ Total } \\
\hline
\end{tabular}

The commonest source of initial identification of speech/language disturbance was a doctor or other member of hospital staff while on treatment for some other condition $(47 \%)$. However, parents have identified the condition initially in $42 \%$ of children. The Medical Officer of Health $(\mathrm{MOH})$ or other members of the $\mathrm{MOH}$ team were involved in initial identification only in $4 \%$ of children.
The age distribution of children seeking formal medical care for speech/language disorder is shown in table 4.

Table 4

Age distribution of children seeking formal medical care for speech /language disorder for first time

\begin{tabular}{|c|c|}
\hline $\begin{array}{c}\text { Age at care seeking } \\
\text { (months) }\end{array}$ & Frequency (\%) \\
\hline$<12$ & $99(38.8)$ \\
\hline $13-24$ & $51(20.0)$ \\
\hline $25-36$ & $19(07.5)$ \\
\hline $37-48$ & $07(02.7)$ \\
\hline $49-60$ & $0(0.0)$ \\
\hline $61-72$ & $0(0.0)$ \\
\hline $73-84$ & $0(0.0)$ \\
\hline $85-96$ & $02(0.8)$ \\
\hline $97-108$ & $0(0.0)$ \\
\hline $109-120$ & $0(0.0)$ \\
\hline$>120$ & $\mathbf{2 5 5 ( 1 0 0 )}$ \\
\hline Total & \\
\hline
\end{tabular}

The mean age of children at care seeking was 18.3 $(\mathrm{SD}=13.3$ ) months. In $89 \%$ of the study subjects parents have sought care or were directed to seek care before the completion of 3 years. 
The sources where parents first sought formal medical care for speech/language disorders is shown in table 5 .

Table 5

Sources where parents first sought formal medical care for speech/language disorders

\begin{tabular}{|c|c|}
\hline Source & Frequency $(\%)$ \\
\hline General practitioner & $37(14.5)$ \\
\hline Hospital / Gov. dispensary OPD & $105(41.2)$ \\
\hline Paediatrician & $47(18.4)$ \\
\hline ENT Surgeon & $04(01.6)$ \\
\hline Child psychiatrist & $05(02.0)$ \\
\hline Speech therapist & $0(0.0)$ \\
\hline MOH team & $04(01.6)$ \\
\hline $\begin{array}{l}\text { Not sought care on your own } \\
\text { but referred by somebody }\end{array}$ & $53(20.8)$ \\
\hline Total & $255(100)$ \\
\hline
\end{tabular}

Many (41\%) parents have sought care for speech / language disorder from a medical officer in a government hospital or a dispensary. Paediatricians (18\%) and General Practitioners (14.5\%) were the other common sources of care seeking. The time gap between initial identification and seeking of formal medical care is shown in table 6 .

Table 6

Time gap between initial identification and seeking of formal medical care

\begin{tabular}{|c|c|}
\hline Time gap & Frequency (\%) \\
\hline$<1$ month & $63(24.7)$ \\
\hline $1-3$ months & $90(35.3)$ \\
\hline $4-6$ months & $41(16.1)$ \\
\hline $7-9$ months & $44(17.3)$ \\
\hline $10-12$ months & $03(1.2)$ \\
\hline$>12$ months & $14(5.5)$ \\
\hline Total & $\mathbf{2 5 5 ( 1 0 0 )}$ \\
\hline
\end{tabular}

The mean time gap was 3.0 (SD 3.3) months. The time gap was more than 3 months in $40 \%$ and more than 12 months in $5.5 \%$ of the study subjects.

The differences between the mean time gap of initial identification to seeking formal medical care for speech/language disorders in selected groups is shown in table 7 .

Table 7

Differences between the mean time gaps of initial identification to seeking formal medical care for speech / language disorders in selected groups

\begin{tabular}{|l|c|c|c|}
\hline \multicolumn{1}{|c|}{ Compared groups } & $\begin{array}{c}\text { Difference of means } \\
\text { (months) }\end{array}$ & $\begin{array}{c}\text { CI for the } \\
\text { difference }\end{array}$ & Significance \\
\hline Male / Female & -0.2321 & $(-1.0599)-0.5958$ & $\mathrm{P}=0.581$ \\
\hline Birth order=1 / Birth order $>1$ & 0.5855 & $(-0.2253)-1.3963$ & $\mathrm{P}=0.152$ \\
\hline Unilingual Families / Bi/tri lingual families & 1.4525 & $0.7424-2.1625$ & $\mathrm{P}=0.000$ \\
\hline Social class 1 \&11 / Social class 111,1V,V & 0.0530 & $(-0.7673)-0.8733$ & $\mathrm{P}=0.894$ \\
\hline Father's educational level <O/L / Passed O/L or & -0.3551 & $(-1.1486)-0.4383$ & $\mathrm{P}=0.377$ \\
above & & $(-1.3571)-0.7555$ & $\mathrm{P}=0.561$ \\
\hline Mother's educational level $<$ O/L / Passed O/L or \\
above
\end{tabular}

Distribution of ages at referral for speech therapy of children with speech / language disorders is shown in table 8. 
Table 8

Distribution of the ages at referral for speech therapy of children with speech / language disorders

\begin{tabular}{|c|c|}
\hline $\begin{array}{c}\text { Age at referral } \\
\text { (months) }\end{array}$ & Frequency (\%) \\
\hline$<12$ & $66(25.9)$ \\
\hline $13-24$ & $80(31.4)$ \\
\hline $25-36$ & $57(22.4)$ \\
\hline $37-48$ & $27(10.6)$ \\
\hline $49-60$ & $08(03.1)$ \\
\hline $61-72$ & $08(03.1)$ \\
\hline $73-84$ & $02(0.8)$ \\
\hline $85-96$ & $05(2.0)$ \\
\hline $97-108$ & $0(0.0)$ \\
\hline $109-120$ & $02(0.8)$ \\
\hline$>120$ & $00(0.0)$ \\
\hline Total & $\mathbf{2 5 5 ( 1 0 0 )}$ \\
\hline
\end{tabular}

Mean age of children at referral was 24.3 (SD 19.6) months. Even though $42.7 \%$ of children were identified to have a speech disability within the first year of life only $25.9 \%$ have been referred within the first year. However 203 (79.6\%) children were referred before completion of 3 years.

Distribution of the source of referral of children with speech and language disorders for speech therapy is shown in table 9.

Table 9

Distribution of source of referral of children with speech / language disorders for speech therapy

\begin{tabular}{|l|c|}
\hline \multicolumn{1}{|c|}{ Source of referral } & $\begin{array}{c}\text { Frequency } \\
(\mathbf{\%})(\mathbf{N}=\mathbf{2 5 5})\end{array}$ \\
\hline MO/OPD (LRH) -via VP/OPD & $13(05.1)$ \\
\hline GP -via VP/OPD & $02(0.8)$ \\
\hline MOH team -via VP/OPD & $04(01.6)$ \\
\hline Paediatrician (LRH) & $26(10.2)$ \\
\hline Paediatrician (other hospital) & $13(05.1)$ \\
\hline ENT Surgeon (LRH) & $24(09.4)$ \\
\hline ENT Surgeon (other hospital) & $20(07.8)$ \\
\hline Paediatric Surgeon (LRH) & $03(01.2)$ \\
\hline Plastic Surgeon (LRH) & $64(25.1)$ \\
\hline Child psychiatrist (LRH) & $15(05.9)$ \\
\hline Child psychiatrist (other hospital) & $03(01.2)$ \\
\hline Rheumatologist (LRH) & $68(26.7)$ \\
\hline
\end{tabular}

The time gap between age at seeking formal medical care and age at referral for speech therapy clinic at LRH is shown in table 10 .
Table10

Time gap between age at seeking formal medical care and age at referral for speech therapy clinic at LRH

\begin{tabular}{|l|c|}
\hline \multicolumn{1}{|c|}{ Time gap } & Number (\%) \\
\hline$<1$ month & $81(31.8)$ \\
\hline $1-3$ months & $68(26.7)$ \\
\hline $4-6$ months & $41(16.1)$ \\
\hline $7-9$ months & $22(8.6)$ \\
\hline $10-12$ months & $08(3.1)$ \\
\hline$>12$ months & $35(13.7)$ \\
\hline Total & $\mathbf{2 5 5 ( 1 0 0 )}$ \\
\hline
\end{tabular}

The mean time gap was 5.9 months. The time gap between age at seeking of formal medical care and age at referral was more than 3 months in $41.6 \%$ of children.

The time gap between age at initial identification of speech/language disorders and age at referral is shown in table 11.

Table 11

Time gap between age at initial identification of speech / language disorders and age at referral

\begin{tabular}{|c|c|}
\hline Time gap & Number (\%) \\
\hline$<1$ month & $27(10.6)$ \\
\hline $1-3$ months & $59(23.1)$ \\
\hline 4-6 months & 47 (18.4) \\
\hline 7-9 months & $40(15.7)$ \\
\hline $10-12$ months & $17(06.7)$ \\
\hline$>12$ months & $65(25.5)$ \\
\hline Total & $255(100)$ \\
\hline
\end{tabular}

The mean time gap was 8.9 months. Time gap between age at initial identification and age at referral was more than 3 months in $66.3 \%$ of children and more than 12 months in $25.5 \%$ of children.

\section{Discussion}

The male: female ratio of the study sample was 1.6: 1.0 which is consistent with studies done locally and internationally $y^{3,5,17-19}$. Ascertainment bias due to over diagnosis and higher reporting in boys was examined by Choudhry et al and persistence of gender differences was shown with measures taken to minimize such bias $^{20}$.

Early identification is important for early intervention. The mean age of initial identification was 15.3 months, in $43 \%$ identification being made before 12 months, and in $91 \%$ before 3 years of age. When compared with other clinic based studies ${ }^{10-12,19}$, 
these values are encouraging. In our study higher maternal educational level was significantly associated with earlier identification $(\mathrm{p}<0.05)$. Higher maternal education level leading to better child development has been consistently seen in many studies $^{5,17}$. Having a positive family history $(\mathrm{p}<0.05)$, being an extended family $(\mathrm{p}<0.001$, $)$, having an associated condition $(\mathrm{p}<0.001)$ and being a girl $(p=0.001)$ were also significantly associated with an earlier age of identification in our study.

The main source of identification in our study was a doctor or another health care worker while in the hospital for some other condition (47\%). However, $42 \%$ of children's speech or language problem was identified by one or other parent. The $\mathrm{MOH}$ team was involved in identification only in $4.3 \%$ of children, which, however, is an improvement when compared with previous studies ${ }^{19}$.

Earlier age of identification does not necessarily mean that care was sought for these children at an early age as shown in many studies both here and abroad $^{10-12}$. The mean age of care seeking in this study group was 18.3 months. The mean time gap between identification and care seeking was 3.0 months. Time gap was more than 3 months for $40 \%$ of the children studied and in $5.5 \%$ of children it was more than 12 months. This time gap could depend on the child as well as family characteristics. A significantly lesser time gap was seen in multilingual families when compared with mono lingual ( $p$ $<0.001$ ), probably because deep rooted concerns that multilingualism can cause speech/language problems made such parents seek care earlier.

Other factors significantly associated with lesser time gap were being an extended family $(p=0.001)$ and having an employed mother $(\mathrm{p}<0.001)$. Birth order of $>1$ or positive family history failed to record any significant lessening of the time gap. Most parents (57.1\%) have sought care from a doctor or other health worker in the primary health care setting, consistent with a previous study done on children with developmental problems ${ }^{19}$.

When considering the ages of referral, $80 \%$ of the study sample were referred for speech therapy before the age of 3 years which is "early referral" according to the available standards ${ }^{5,7}$. The mean age of referral to speech and language therapy clinic was 24.2 months. However on analyzing the time gap between age of care seeking and referral, the mean gap was 5.9 months, whereas the gap was more than 3 months in $41.6 \%$ of children. The mean gap between initial identification and referral was 8.9 months and the gap was more than 3 months in $66 \%$ of children. This is probably a result of multiple points of contact before being referred as shown in previous studies too ${ }^{19}$. Even though the parents have sought care primarily from a primary health care worker the referrals show a different pattern with $93 \%$ of referrals being done by a child specialist within or outside LRH. These are indications of relative unawareness of health care workers of speech therapy and its importance.

\section{Conclusions and recommendations}

- The current timeliness of disease identification is encouraging with a mean of 15 months but there is room for improvement with regard to the ages of identification especially in the otherwise healthy children.

- Awareness programmes should be carried out for primary health care workers (Medical Officers/ Outpatient Department, General Practitioners, $\mathrm{MOH})$ on the availability of facilities and need for timely referral.

- Every effort should be taken to preserve the traditional extended family system for its known positive effects on child development.

\section{References}

1. American Speech Language Hearing Association. What is language / what is speech? [home page on the internet].c 2010 [cited 2010 June 20]. Available at: http://www.asha.org/public/speech/development/ language-speech.htm

2. Law J, Garrett Z, Nye C. Speech and language therapy interventions for children with primary speech and language delay or disorder. Cochrane Database of Systematic Reviews, 2003, Issue 3.CD004110. http://dx.doi.org/10.1002/14651858.CD004110

3. Ariyaratne AKSK. An evaluation of an intervention programme on child mental health activities [unpublished thesis MD]. Post Graduate Institute of Medicine: University of Colombo; 1996.

4. Perera H, Gunatunga C. Screening for mental health problems in preschool children- a pilot study. Sri Lanka Journal of Child Health. 2004; 33: 39-42. 
5. United States Preventive Services Task Force. Screening for speech and language delay in preschool children: recommendation statement. Pediatrics.2006; 117(2): 497-501.

http://dx.doi.org/10.1542/peds.2005-2766

6. Sharp HM, Hillenbrand K. Speech and language development and disorders in children. Pediatric Clinics of North America 2008; 55(5): 1159-73. http://dx.doi.org/10.1016/j.pcl.2008.07.007

7. American Speech-Language-Hearing Association. Preferred practice patterns for the profession of speech-language pathology; 2004. [home page on the internet]. C 2010 [cited 2010 April 29]. Available at: http:/www.asha.org/NR/rdonlyres/ html

8. Harris R. California Speech Language and Hearing Association. Preferred practice patterns for speech-language pathologists in service delivery to infants and toddlers and their families: Guidelines for Intervention Planning and Delivery; 2002 [home page on the internet]. [cited 2010 June 15]. Available at: $<\underline{\text { http://www.cshl.org.com }>}$

9. ARC Speech and Language Clinic; North Dublin .Speech therapy - Frequently asked questions; 2010. [home page on the internet] [cited 2010 April 29]. Available at: $<\underline{\text { http://www.arcspeech.ie/home }}>$

10. Chakrabarti S. Early identification of autism Indian Pediatrics. 2009; 46: 411-4.

11. Wijeratne WGTGD, Wijesekera NW, Wijesinghe RT, Kariyawasam SH. Learning difficulties in children attending a special clinic at the Lady Ridgeway Hospital Sri Lanka. Sri Lanka Journal of Child Health 2003; 32: 96-104.

12. Perera H, Perera R. User satisfaction with child psychiatry outpatient care: implications for practice. Ceylon Medical Journal.1998; 43(4): 185-90.

13. Kodikara S. Needs for services for children with communication disabilities in Sri Lanka.[unpublished dissertation]. Institute of Child health: University College: London; 1999. [Cited on 2010 June 06]. Available at <http://www.ucl.ac.uk/ich/services/library/sourc e/cihddissertations/disabilitystudiestitles
14. Wickenden M, HartleS, Kariyakaranawa S, KodikaraS. Teaching speech and language therapists in Sri Lanka: Issues in curriculum, culture and language. International Journal of Phoniatrics, Speech Therapy and Communication Pathology 2003; 55(6): 314-32.

15. Wijesinghe $\mathrm{T}$; University of Arkansas; Fayetteville; USA. Education and training in 2 nations. C.2013. [Cited on 2013 August 25]. Available from: http://div10perspectives.asha.org/content/13/1/18 full.pdf

16. Perera I. Speech therapy in Sri Lanka. Oral presentation at symposium on disability: Annual Scientific Sessions, Sri Lanka Medical Association: 2010; Colombo; Sri Lanka.

17. Keegstra AL, Knijff WA, Post WJ, Brouwer SMG. Children with language problems in a speech and hearing clinic: background variables and extent of language problems. International Journal of Pediatric Otorhinolaryngology 2007; 71(5): 815-21. http://dx.doi.org/10.1016/j.ijporl.2007.02.001

18. Broomfield J, Dodd B. Children with speech and language disability: caseload characteristics. Language and Communication Disorders. 2004; 39(3): 303-24. http://dx.doi.org/10.1080/136828203100016255 $\underline{89}$

19. Senanayake MP, Jayamaha DJ, De Silva TUN, Bahirathan S. Pathways taken by parents of disabled children. Sri Lanka Journal of Child Health. 2000; 45(4): 46-58.

20. Choudhury N, Benasich AA. A family aggregation study: The influence of family history and other risk factors on language development. Journal of Speech, Language and Hearing Research 2003; 46 (2): 261-72. http://dx.doi.org/10.1044/1092-4388(2003/021) 